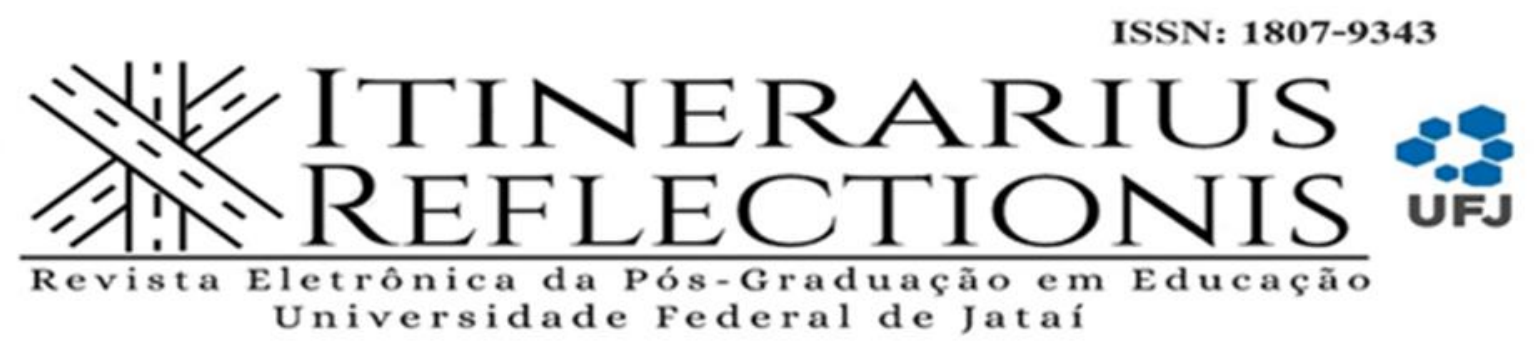

\title{
Metodologia ativa de aprendizagem no plano municipal de educação de Jataí-Go 1
}

Rodolfo Costa Cunha ${ }^{2}$

Resumo A pesquisa objetivou analisar o Plano Municipal de Educação (PME) de Jataí - GO, para evidenciar se a Metodologia Ativa de Aprendizagem (MAA) compõe as estratégias de melhoria do ensino na Educação de Jovens e Adultos e na Educação Profissional e Tecnológica. Para isso, analisaram-se três metas do PME (7, 10 e 11). Utilizou-se a pesquisa exploratória, análise de conteúdo e a técnica de análise documental. Considerou-se, como unidade de registro, a expressão: Metodologia Ativa de Aprendizagem. Escolheu-se a contagem por frequência simples. Observou-se frequência zero. Concluiu-se que a MAA não compõe as estratégias educacionais do PME, nas modalidades supracitadas.

Palavras-chave: Metodologia Ativa de Aprendizagem. Educação de Jovens e Adultos. Educação Profissional e Tecnológica. Plano Municipal de Educação.

Abstract The research aimed to analyze the Municipal Education Plan (PME) of Jataí - GO, to show if the Active Learning Methodology (MAA) composes the strategies for improving teaching in Youth and Adult Education and in Professional and Technological Education. For this, three SME targets (7, 10 and 11) were analyzed. Exploratory research, content analysis and document analysis technique were used. The expression: Active Learning Methodology was considered as the recording unit. Counting by simple frequency was chosen. Zero frequency was observed. It was concluded that the MAA does not compose the educational strategies of the PME, in the aforementioned modalities.

Keywords: Active Learning Methodology. Youth and Adult Education. Professional and Technological Education. Municipal Education Plan.

\section{INTRODUÇÃO}

\footnotetext{
1 O presente artigo é um requisito necessário para a Conclusão do Curso de Pós-graduação lato sensu em Docência na Educação Profissional Técnica e Tecnológica - Modalidade a Distância, ofertado pelo Instituto Federal de Goiás (IFG) - Campus Jataí-GO em parceria com a Universidade Aberta do Brasil (UAB).

${ }^{2}$ Acadêmico do Curso de Pós-Graduação IFG. Campus Jataí. rodolfocosta@ufj.edu.br
} 


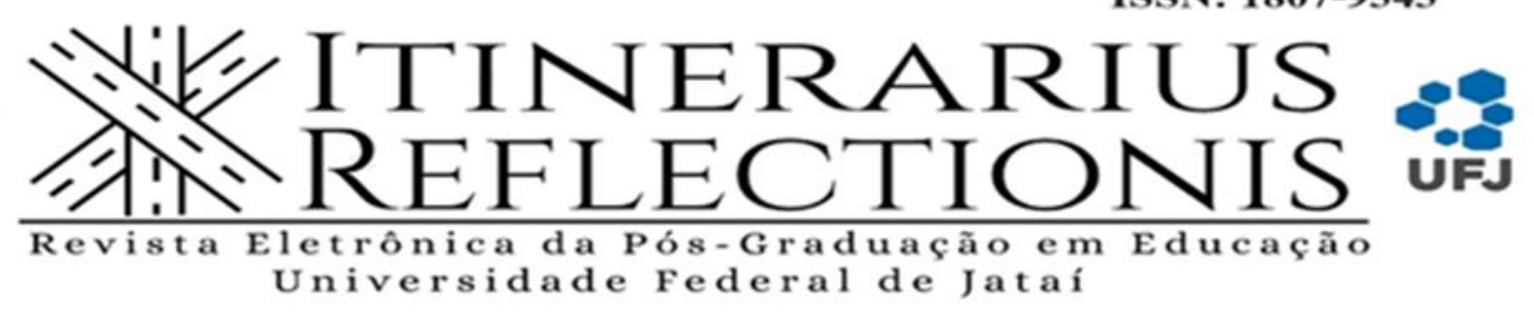

2

O clima escolar refere-se a um dos quesitos avaliados no Programa Internacional de Avaliação de Estudantes (PISA). O "índice sobre clima escolar entre professores foi criado com base nas respostas ao questionário das escolas, por diretores ou pessoas designadas por eles" (PISA, 2015, p. 215), o índice demonstra qual é o grau de concordância com as seguintes afirmações: funcionários que resistem a mudança; falta de assiduidade dos professores; atitude severa demais dos professores com os alunos; professores que não estão bem preparados para lecionar; professores que não identificam as necessidades individuais dos alunos. Por tanto, quanto maior o índice, maior é grau de concordância com as afirmações.

O Brasil apresenta um índice $(0,3)$ que demonstra uma diferença considerável quando comparado à Coreia do Sul (-0,5), país com melhor índice. No Brasil, a afirmação que apresentou maior grau de concordância foi sobre a resistência a mudanças dos funcionários, seguida da afirmação sobre a não identificação dos professores quanto às necessidades dos alunos; a falta de assiduidade dos professores; professores que não estão bem preparados; e, por último, atitudes severas demais dos professores com os alunos.

Com os fatos apresentados, podemos concluir que a falta de inovação é percebida nos ambientes escolares, uma vez que, para inovar são necessárias mudanças e engajamento por parte dos envolvidos no contexto educacional, algo que não é entendido, já que os funcionários apresentam resistência a mudanças.

O fato de que os professores têm pouca percepção das necessidades individuais do aluno, pode estar relacionado aos métodos de ensino. No Brasil, o método mais utilizado é o de aulas expositivas, em que o professor é o protagonista e não os alunos, permitindo pouca interação com os alunos e dificultando o diagnóstico das necessidades individuais dos mesmos. Segundo Vasconcellos (1992, p. 2), "problema da metodologia expositiva, do ponto de vista pedagógico, é seu alto risco de não aprendizagem, justamente em função do baixo nível de interação sujeitoobjeto de conhecimento, ou seja, o grau de probabilidade de interação significativa é muito baixo".

Para que haja uma mudança na qualidade educacional, o Brasil precisa repensar a concepção de educar, quebrar as resistências existentes no ambiente escolar e promover a cultura da inovação nas instituições de ensino. A Metodologia Ativa de Aprendizagem (MAA) 


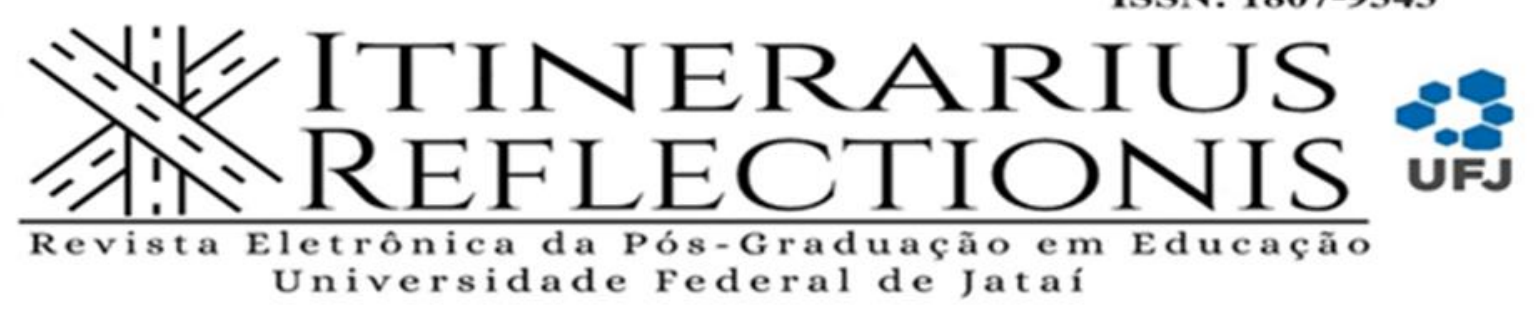

3

é uma das inovações que podem ser trabalhadas em sala de aula, tanto de escolas públicas quanto de escolas privadas. Esta metodologia é uma forma de colocar crianças e jovens no centro da aprendizagem.

Camargo e Daros (2018, p. 22) asseveram que a MAA refere-se a uma "pedagogia dinâmica, centrada na criatividade e na atividade discente, em uma perspectiva de construção do conhecimento, protagonismo, autodidatismo, da capacidade de resolver problemas, do desenvolvimento de projetos, da autonomia e do engajamento" nas atividades de desenvolvimento do processo de ensino-aprendizagem. Logo, a MAA, a partir da exposição de Camargo e Daros (2018), pode ser uma estratégia educacional importante para promover a qualidade da educação em qualquer nível, modalidade e esfera governamental. Desta forma, os municípios precisam estar atentos às diferentes pedagogias de ensino e aprendizagem, colocando-as como estratégia para a melhoria do ensino nas instituições educacionais.

Por meio da exploração documental, esta pesquisa buscou evidências contidas no Plano Municipal de Educação (PME) da cidade de Jataí - GO, referentes ao estímulo da MAA como estratégia para a melhoria do ensino nas modalidades de Educação de Jovens e Adultos (EJA) e na Educação Profissional e Tecnológica, do município.

Para retratar a pesquisa, este artigo apresenta, na sequência desta introdução, o referencial teórico (Plano Municipal de Educação; Metodologia Ativa de Aprendizagem; Educação de Jovens e Adultos e Educação Profissional e Tecnológica), a metodologia (os procedimentos usados na pesquisa), a apresentação e análise dos dados (discussão dos resultados encontrados) e se encerra com as conclusões do mesmo.

\section{REFERENCIAL TEÓRICO}

O referencial teórico abarca a discussão sobre os temas que norteiam a proposta do artigo, aprofundando o entendimento do Plano Municipal de Educação (PME) e trazendo as metas que o compõem; explorando o conceito e a importância da Metodologia Ativa de Aprendizagem (MAA); e, para finalizar, os conceitos sobre a Educação de Jovens e Adultos (EJA) e Educação Profissional e Tecnológica (EPT). 


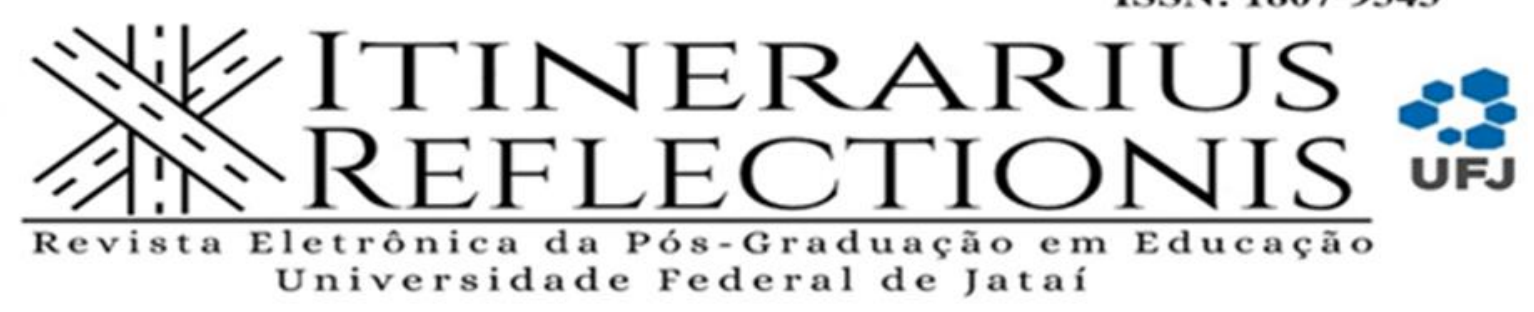

\title{
2. 1 Plano Municipal de Educação (PME)
}

De acordo com o caderno de orientações do Ministério da Educação MEC (2014, p. 7) o PME

\begin{abstract}
é de todos que moram no município; portanto, todas as necessidades educacionais do cidadão devem estar presentes no Plano, o que vai muito além das possibilidades de oferta educacional direta da Prefeitura. Também não se trata do plano de uma administração da Prefeitura ou da Secretaria Municipal de Educação, pois atravessa mandatos de vários prefeitos e dirigentes municipais de educação.
\end{abstract}

Essa característica do PME, relatada acima, é importante. É um documento que não sofrerá alterações nas estratégias propostas para a educação municipal, por influências políticas momentâneas, o que garante credibilidade ao documento. O MEC (2014, p. 8) salienta, ainda, que:

o PME terá a responsabilidade de traduzir e conciliar os desejos, as necessidades e as capacidades educacionais do município para a oferta da educação básica (em todas as suas etapas e modalidades) e também de ensino superior. Precisa levar em consideração a trajetória histórica, as características socioculturais e ambientais, a vocação e a perspectiva de futuro do município.

O destaque, presente no MEC (2014), revela o potencial de organização e planejamento de ações no âmbito da Educação. Portanto, esse documento norteador precisa ser construído de modo coletivo e cooperativo por todos os representantes da comunidade escolar e acadêmica do município. O debate, as escolhas e o conhecimento profundo da realidade da população devem balizar as decisões. Assim, o $\operatorname{MEC}(2014$, p. 8) chama a atenção para a necessidade de:

conhecer bem o cenário atual para projetar o futuro com base em decisões coerentes e pactuadas. A efetividade do PME depende em grande parte do real dimensionamento das demandas educacionais, das fragilidades, dos desafios e das potencialidades do município. Essas demandas e necessidades precisam ser comparadas com a capacidade atual e futura de investimentos da Prefeitura e possíveis aportes do governo estadual, da União e de outras fontes. 


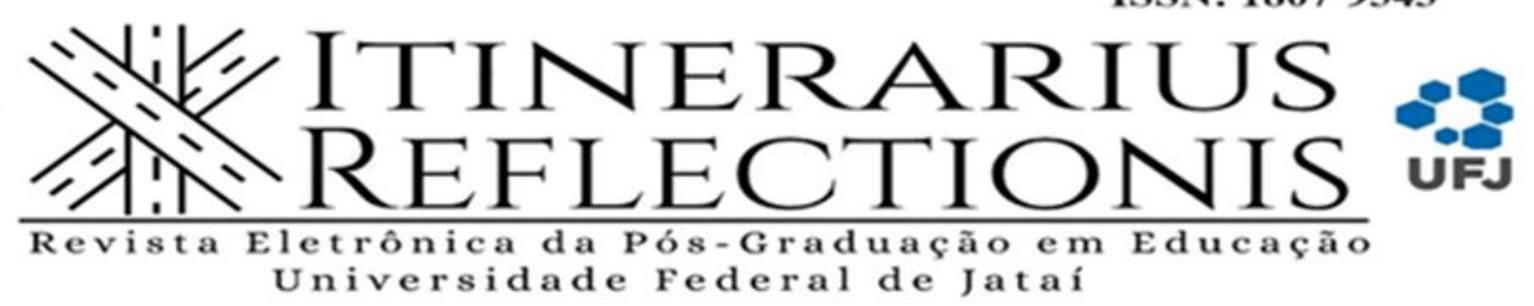

As diretrizes do MEC (2014) deixam claro que o PME deve ser pensado de acordo com as carências e dificuldades de cada município. Por tanto, é fundamental a instalação de uma equipe que conheça a realidade das salas de aula; dos obstáculos enfrentadas pelos alunos, professores e coordenadores; das diferenças entre as zonas rurais e urbanas; e as peculiaridade dos níveis educacionais. Essa equipe deve dialogar com representantes de todas as entidades educacionais e organizações civis para conseguir ter contribuições que contemplem os anseios e necessidades da comunidade local.

O PME, do município de Jataí-GO, foi elaborado, segundo o Diário Oficial (516 edição, 2015), "por um Grupo Gestor, representativo de toda a sociedade, o qual competiu à coordenação do desenvolvimento do processo de construção e promoção do PME, confirmando a importância da articulação com todos os entes envolvidos na Educação", no contexto do município. A construção do PME se deu de maneira democrática e participativa, segundo consta nesse documento.

O PME de Jataí-GO está estruturado com 20 (vinte) metas e dentro de cada uma existem inúmeras estratégias para alcançar objetivos pontuais. Conforme Diário Oficial $\left(516^{\circ}\right.$ edição, 2015), às metas do PME são:

Quadro 1: Metas

\begin{tabular}{|c|l|}
\hline $\mathbf{N}^{\mathbf{0}}$ & \multicolumn{1}{c|}{ METAS } \\
\hline $\mathbf{1}$ & $\begin{array}{l}\text { Universalizar, até 2016, a educação infantil na pré-escola para as crianças de 4 (quatro) a 5 (cinco) } \\
\text { anos de idade e ampliar a oferta de educação infantil em creches de forma a atender, no mínimo, } \\
50 \% \text { (cinquenta por cento) das crianças de até 3 (três) anos até o final da vigência deste PME; }\end{array}$ \\
\hline $\mathbf{2}$ & $\begin{array}{l}\text { Universalizar o ensino fundamental de 9 (nove) anos para toda a população de 6 (seis) a 14 } \\
\text { (quatorze) anos e garantir que pelo menos 95\% (noventa e cinco por cento) dos alunos concluam } \\
\text { essa etapa na idade recomendada, até o último ano de vigência deste PME; }\end{array}$ \\
\hline $\mathbf{3}$ & $\begin{array}{l}\text { Universalizar, até 2016, pelo governo do Estado, o atendimento escolar para toda a população de } \\
\text { 15 (quinze) a 17 (dezessete) anos e elevar, até o final do período de vigência deste Plano } \\
\text { Municipal de Educação, a taxa líquida de matrículas no ensino médio para 85\% (oitenta e cinco } \\
\text { por cento); }\end{array}$ \\
\hline $\mathbf{4}$ & $\begin{array}{l}\text { Universalizar, para a população de 4 (quatro) a 17 (dezessete) anos com deficiência, transtornos } \\
\text { globais do desenvolvimento e altas habilidades ou superdotação, o acesso à educação básica e ao } \\
\text { atendimento educacional especializado, preferencialmente na rede regular de ensino, com a }\end{array}$ \\
\hline
\end{tabular}




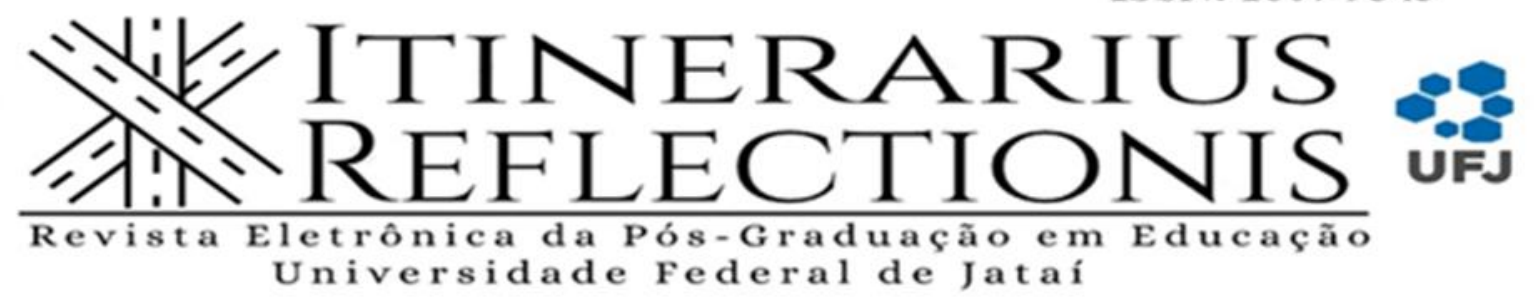

6

\begin{tabular}{|c|c|}
\hline & $\begin{array}{l}\text { garantia de sistema educacional inclusivo, de salas de recursos multifuncionais, classes, escolas } \\
\text { ou serviços especializados, públicos ou conveniados; }\end{array}$ \\
\hline 5 & Alfabetizar todas as crianças, no máximo, até o final do $3^{\circ}$ (terceiro) ano do ensino fundamental; \\
\hline 6 & $\begin{array}{l}\text { Oferecer educação em tempo integral em, no mínimo, } 50 \% \text { (cinquenta por cento) das escolas } \\
\text { públicas, de forma a atender, pelo menos, } 25 \% \text { (vinte e cinco por cento) dos (as) alunos (as) da } \\
\text { educação básica; }\end{array}$ \\
\hline 7 & $\begin{array}{l}\text { Fomentar a qualidade da educação básica em todas as etapas e modalidades, com melhoria do } \\
\text { fluxo escolar e da aprendizagem de modo a atingir as seguintes médias nacionais para o IDEB; }\end{array}$ \\
\hline 8 & $\begin{array}{l}\text { Elevar a escolaridade média da população de } 18 \text { (dezoito) a } 29 \text { (vinte e nove) anos, de modo a } \\
\text { alcançar, no mínimo, } 12 \text { (doze) anos de estudo no último ano de vigência deste plano, para as } \\
\text { populações rurais e dos } 25 \% \text { (vinte e cinco por cento) mais pobres, e diminuindo a desigualdade } \\
\text { da escolaridade média entre negros e, não negros, declarados à Fundação Instituto Brasileiro de } \\
\text { Geografia e Estatística - IBGE; }\end{array}$ \\
\hline 9 & $\begin{array}{l}\text { Elevar a taxa de alfabetização da população com } 15 \text { (quinze) anos ou mais para } 93,5 \% \text { (noventa } \\
\text { e três inteiros e cinco décimos por cento) até } 2015 \text { e, até o final da vigência deste PME, erradicar } \\
\text { o analfabetismo absoluto e reduzir em } 50 \% \text { (cinquenta por cento) a taxa de analfabetismo } \\
\text { funcional; }\end{array}$ \\
\hline 10 & $\begin{array}{l}\text { Oferecer, no mínimo, } 25 \% \text { (vinte e cinco por cento) das matrículas de educação de jovens e } \\
\text { adultos, nos ensinos fundamental e médio, na forma integrada à educação profissional; }\end{array}$ \\
\hline 11 & $\begin{array}{l}\text { Triplicar as matrículas da educação profissional técnica de nível médio, assegurando a qualidade } \\
\text { da oferta e pelo menos } 50 \% \text { (cinquenta por cento) da expansão no segmento público; }\end{array}$ \\
\hline 12 & $\begin{array}{l}\text { Elevar a taxa bruta de matrícula na educação superior para } 50 \% \text { (cinquenta por cento) e a taxa } \\
\text { líquida para } 33 \% \text { (trinta e três por cento) da população de } 18 \text { (dezoito) a } 24 \text { (vinte e quatro) anos, } \\
\text { assegurada à qualidade da oferta e expansão para, pelo menos, } 40 \% \text { (quarenta por cento) das } \\
\text { novas matrículas, no segmento público; }\end{array}$ \\
\hline 13 & $\begin{array}{l}\text { Elevar a qualidade da educação superior e ampliar a proporção de mestres e doutores do corpo } \\
\text { docente em efetivo exercício no conjunto do sistema de educação superior para } 75 \% \text { (setenta e } \\
\text { cinco por cento), sendo, do total, no mínimo, } 35 \% \text { (trinta e cinco por cento) doutores; }\end{array}$ \\
\hline 14 & $\begin{array}{l}\text { Elevar gradualmente o número de matrículas na pós-graduação stricto sensu, ampliando em } 10 \% \\
\text { até } 2019 \text { e } 20 \% \text { até } 2024 ;\end{array}$ \\
\hline 15 & $\begin{array}{l}\text { Garantir, em regime de colaboração entre a União, os Estados, o Distrito Federal e os Municípios, } \\
\text { no prazo de } 1 \text { (um) ano de vigência deste PME, política nacional de formação dos profissionais } \\
\text { da educação de que tratam os incisos I, II e III do caput do art. } 61 \text { da Lei no } 9.394 \text {, de } 20 \text { de } \\
\text { dezembro de } 1996 \text {, assegurado que todos os professores e as professoras da educação básica } \\
\text { possuam formação específica de nível superior, obtida em curso de licenciatura na área de } \\
\text { conhecimento em que atuam; }\end{array}$ \\
\hline 16 & $\begin{array}{l}\text { Formar, em nível de pós-graduação, } 50 \% \text { (cinquenta por cento) dos professores da educação } \\
\text { básica, até o último ano de vigência deste PME, e garantir a todos (as) os (as) profissionais da }\end{array}$ \\
\hline
\end{tabular}




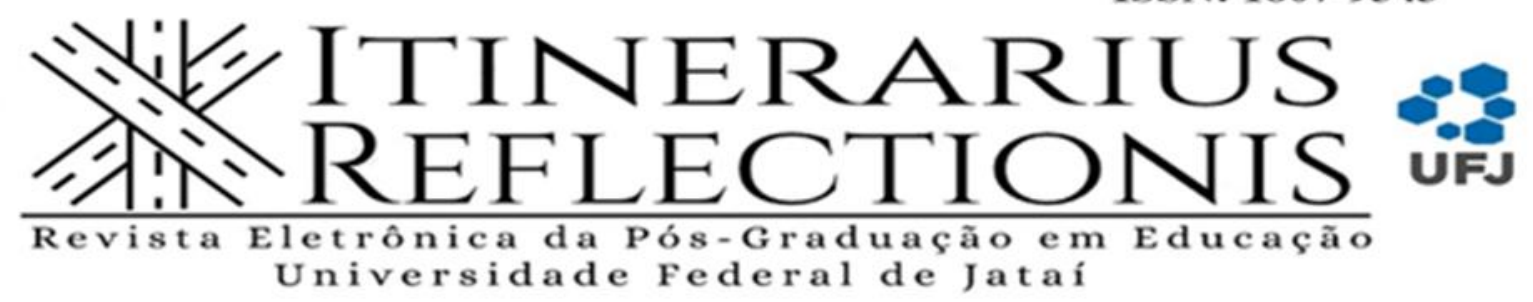

7

\begin{tabular}{|c|l|}
\hline $\mathbf{1 7}$ & $\begin{array}{l}\text { educação básica formação continuada em sua área de atuação, considerando as necessidades, } \\
\text { demandas e contextualizações dos sistemas de ensino; }\end{array}$ \\
\hline $\mathbf{1 8}$ & $\begin{array}{l}\text { Valorizar os (as) profissionais do magistério das redes públicas de educação básica de forma a } \\
\text { equiparar seu rendimento médio ao dos (as) demais profissionais com escolaridade equivalente, } \\
\text { até o final do sexto ano de vigência deste PME; }\end{array}$ \\
\hline $\mathbf{1 9}$ & $\begin{array}{l}\text { Assegurar, no prazo de 2 (dois) anos, a existência de planos de Carreira para os (as) profissionais } \\
\text { dos (as) profissionais da educação básica pública, tomar como referência o piso salarial nacional } \\
\text { profissional, definido em lei federal, nos termos do inciso VIII do art. 206 da Constituição }\end{array}$ \\
$\begin{array}{l}\text { Federal. } \\
\text { Assegurar condições, no prazo de 2 (dois) anos, para a efetivação da gestão democrática da } \\
\text { educação, associada a critérios técnicos de mérito e desempenho e à consulta pública à } \\
\text { comunidade escolar, no âmbito das escolas públicas, prevendo recursos e apoio técnico da União } \\
\text { para tanto; }\end{array}$ \\
\hline $\mathbf{2 0}$ & $\begin{array}{l}\text { Ampliar o investimento público em educação pública de forma a atingir, no mínimo, o patamar } \\
\text { de 7\% (sete por cento) do Produto Interno Bruto - PIB do País no 5º (quinto) ano de vigência } \\
\text { desta Lei e, no mínimo, o equivalente a 10\% (dez por cento) do PIB ao final do decênio. }\end{array}$ \\
\hline
\end{tabular}

Fonte: Diário Oficial (nº. $516^{\circ}$ edição, 2015). Adaptado durante a pesquisa.

Como visto, o PME é um documento que precisa ser bem planejado antes da sua elaboração, pois influenciará as estratégias para melhoria da educação como um todo, do ensino básico ao superior, por um período de 10 (dez) anos. Portanto, é um documento fundamental para direcionar a educação municipal e rico em informações (diretrizes do PME; diagnóstico da realidade educacional municipal em todos seus níveis e modalidade; e plano de metas) que poderá ser usado para inúmeras pesquisas na área da educação.

\subsection{Metodologia Ativa de Aprendizagem (MAA)}

Há diferentes metodologias de aprendizagem e uma delas é a MAA. Segundo Barbosa e Moura (2013, p. 55), "para se envolver ativamente no processo de aprendizagem, o aluno deve ler, escrever, perguntar, discutir ou estar ocupado em resolver problemas e desenvolver projetos". A MAA proporciona condições para que o aluno se torne protagonista no processo de aprendizagem e exige do mesmo um maior compromisso com as atividades propostas. $\mathrm{O}$ professor se torna um guia do processo, ajudando o aluno a descobrir o melhor caminho para 


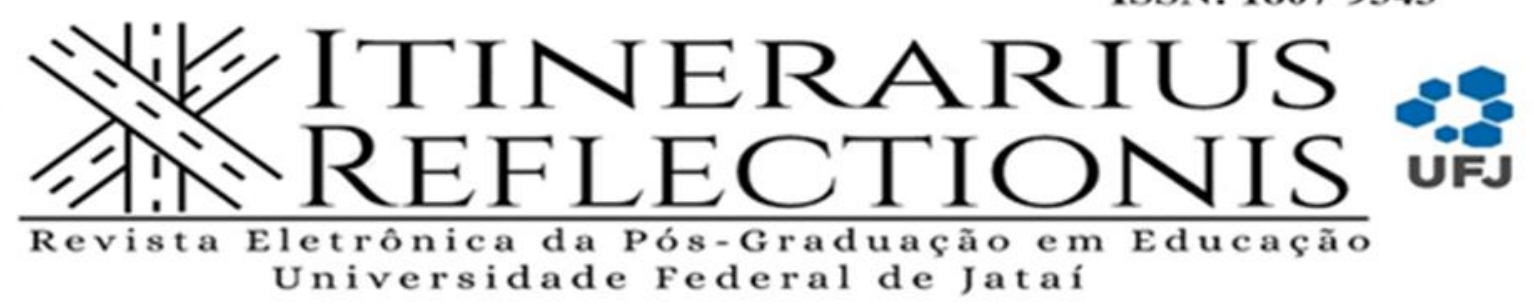

8

resolver as diferentes situações apresentada. Para Ribeiro, apud Barbosa e Moura (2013, p. 56), a aprendizagem ocorre por meio de experiência:

[...] Além disso, os alunos que vivenciam esse método adquirem mais confiança em suas decisões e na aplicação do conhecimento em situações práticas; melhoram o relacionamento com os colegas, aprendem a se expressar melhor oralmente e por escrito, adquirem gosto para resolver problemas e vivenciam situações que requerem tomar decisões por conta própria, reforçando a autonomia no pensar e no atuar.

Os governantes e gestores precisam estar atentos à necessidade de mudança nas escolas públicas brasileiras, para oferecerem à sociedade uma educação de qualidade e alinhada com as utilidades futuras, como por exemplo: o estudo da metacognição, ou seja, ensinar os estudantes a importância do saber como e onde buscar o conhecimento em situações profissionais; valorizar mais as vivências com as diferenças e estimular atitudes positivas em relação ao coletivo. Esses são alguns exemplos para que a escola se torne menos conteudista e mais inclusivas e emancipadoras. Camargo e Daros (2018, p. 25) reforçam essa ideia quando argumentam que:

grande parte das instituições de ensino faz uso de métodos de ensino tradicionais. Ambientes ou salas de aulas ganham nomes como "local onde todos dormem e uma pessoa fala", o que deriva do fato de que o ato de ensinar acaba resumindo-se ao momento da aula expositiva, encerrando-se nele e desconsiderando a ação de ensinar.

Logo, os planos nacionais, estaduais e municipais de educação precisam prever tal mudança, tendo dentro das estratégias de melhoria de educação evidências que permitam afirmar que a implementação da MAA é uma preocupação, pois com estas evidências demonstra a preocupação das autoridades em melhorar o cenário educacional brasileiro para superar a prática tradicional. Vasconcellos $(1992$, p. 1) traz sua visão sobre a prática tradicional, quando diz que "pesquisas pedagógicas demonstram cientificamente aquilo que percebemos pela nossa observação atenta no cotidiano da escola: a situação atual em sala de aula, em grandes linhas, pode ser caracterizada como baseada numa metodologia "tradicional", de cunho academicista".

Por tanto, fica claro a necessidade da mudança do ensino tradicional para todos os níveis de educação, essa mudança pode garantir a competitividade dos alunos brasileiros em comparação aos alunos que vivenciam outros processos educacionais, mais modernos, em 


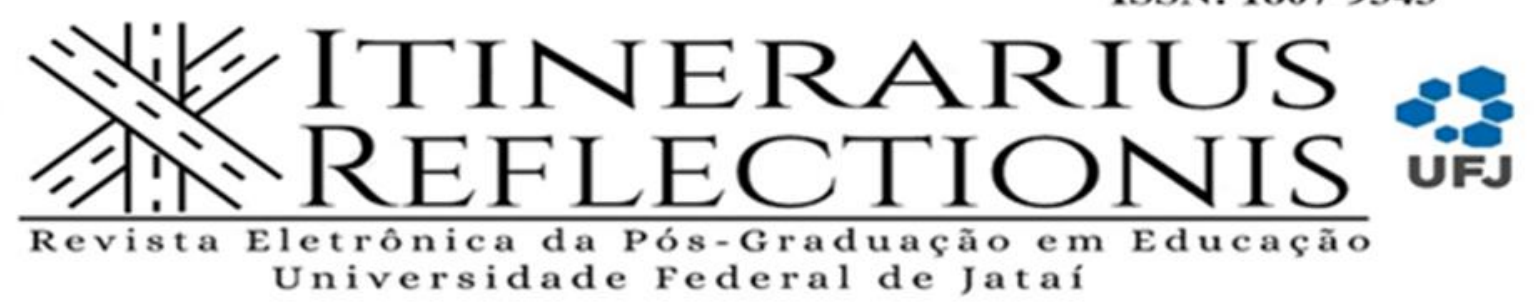

9

diferentes países, possibilitando acesso às melhores oportunidades de emprego e continuidade dos estudos, formando cidadãos preparados para enfrentar circunstâncias que exijam soluções interdisciplinares no contexto global.

\section{Educação de Jovens e Adultos e Educação Profissional e Tecnológica}

No Brasil, existem a modalidade de educação voltada para o público jovem e adulto, conhecida como Educação de Jovens e Adultos (EJA) e a modalidade de Educação Profissional e Tecnológica (EPT). Sousa e Silva (2006, p. 8-9), comentam sobre a Lei de Diretrizes e Bases da Educação Nacional (LDB), nº 9.394, de 20 de dezembro de 1996, que:

Da Educação de Jovens e Adultos, artigos 37 e 38, observa- se que essa modalidade de ensino é destinada àqueles que não tiveram acesso ao ensino ou não puderam dar continuidade aos estudos na idade adequada. Esses estudantes deverão frequentar cursos supletivos, os maiores de 15 anos deverão concluir o ensino fundamental e os estudantes acima de 18 anos deverão concluir o ensino médio.

Fica claro, pela descrição acima, que o EJA é fundamental para a inclusão social e econômica de boa parte da população brasileira, uma vez que, inúmeros jovens precisam começar a trabalhar cedo para sustentar suas famílias e não percebem como a escola poderá auxiliar aquela realidade momentânea. Por isso, é fundamental oportunizar uma nova chance para esses indivíduos, possibilitando uma melhor qualidade de vida, proveniente da educação de qualificação. Sousa e Silva (2006, p. 8-9) comentam, ainda, que:

Educação Profissional e Tecnológica, o art. 39 reza que a educação profissional e
tecnológica agrega as modalidades de educação. Essa educação abrange a formação
inicial e continuada, a formação profissional técnica de nível médio, graduação e pós-
graduação. Nos artigos 40,41 e 42 , menciona que a educação profissional pode ser
desenvolvida através do ensino regular, em instituições especializadas ou em
ambiente de trabalho. O conhecimento adquirido através do trabalho pode ser um
elemento de avaliação e consequentemente de conclusão dos estudos. As instituições
ao ofertarem cursos regulares também poderão ofertar a educação profissional e
tecnológica.

O ensino da Educação Profissional e Tecnológica não pode ser visto como inferior aos outros, ele deve ser tratado, pelas instituições de ensino, com a mesma seriedade que as outras modalidades. É indispensável que os gestores responsáveis pela EPT desmistifiquem a imagem 


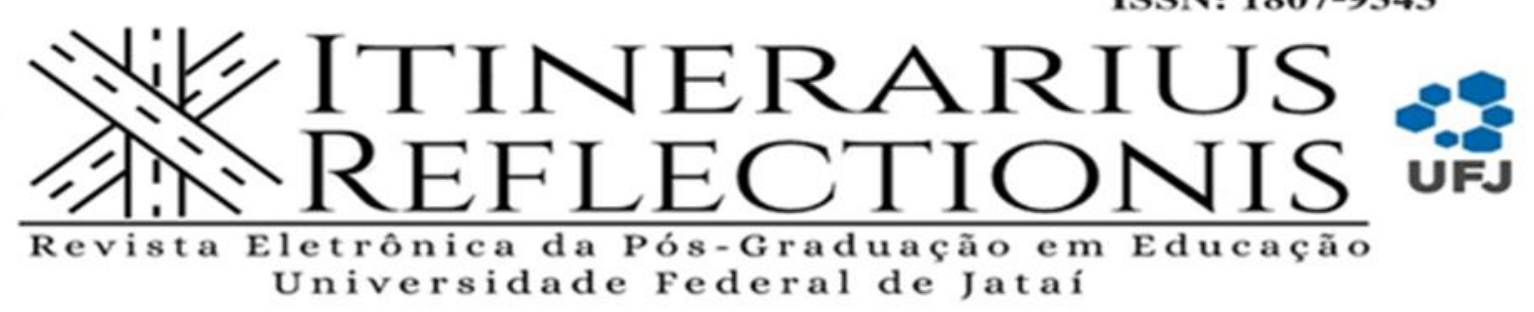

10

que se criou ao longo da história brasileira de que a EPT foi feita para os menos abastados. Amaral e Juk (2017, p. 101) apontam que a criação da EPT nos seus anos iniciais

[...] significou a divisão entre duas classes de estudantes. Por um lado, estudantes com poder aquisitivo recebiam formação intelectual clássica nas escolas privadas. Por outro lado, estudantes sem poder aquisitivo recebiam formação intelectual técnica nas escolas públicas.

Esta divisão de classe favoreceu, até os dias de hoje, a visão equivocada que o EPT é para aqueles que não possuem condição financeira e, por tanto, não precisam de formação intelectual clássica, apenas a formação técnica. As consequências desta distorção é o aumento das diferenças sociais, dificultando a emancipação das classes sociais mais baixas.

Hoje, o Brasil tem o Programa Nacional de Integração da Educação Profissional com a Educação Básica na modalidade de Educação de Jovens e Adultos, o PROEJA. O programa tem como objetivo atender à demanda de jovens e adultos pela oferta de educação profissional técnica de nível médio. Por meio do Decreto ${ }^{\circ}$. 5.840, de 13 de julho de 2006, contemplam como modalidade de EJA os seguintes cursos:

- $\quad$ Educação profissional técnica integrada ao ensino médio;

- $\quad$ Educação profissional técnica concomitante ao ensino médio;

- Qualificação profissional, incluindo a formação inicial e continuada integrada ao ensino fundamental;

- Qualificação profissional, incluindo a formação inicial e continuada concomitante ao ensino fundamental;

- Qualificação profissional, incluindo a formação inicial e continuada integrada ao ensino médio;

- Qualificação profissional, incluindo a formação inicial e continuada concomitante ao ensino médio.

Essas modalidades, assim como as outras, devem ser ofertadas com qualidade e precisam de estratégias próprias para garanti-las. Precisa-se aproveitar da melhor maneira possível a experiência de vida desses alunos, uma vez que, são alunos com mais idade e por consequência já possuem conhecimentos obtidos por elas. A metodologia tradicional não é o mais indicado para estimular a troca de experiências e melhor aproveitamento das mesmas. Por isso, é 


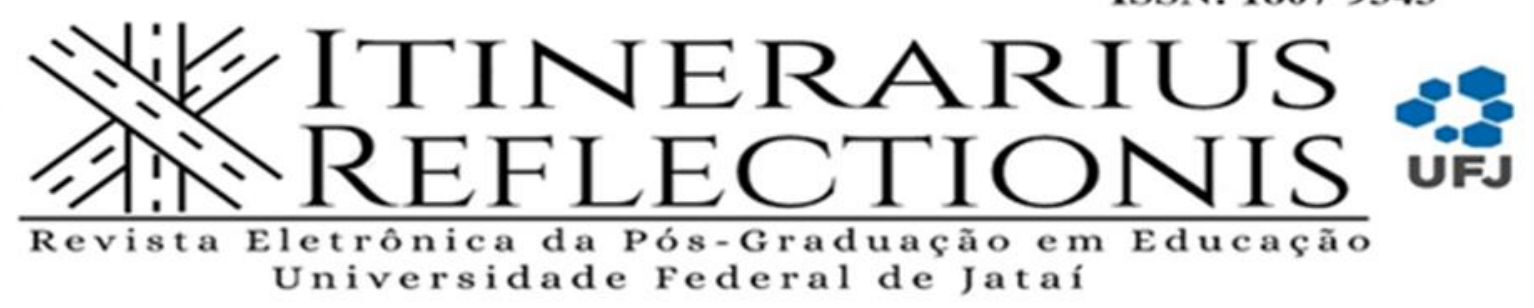

11

importante que dentro das estratégias para o ensino das modalidades EJA e EPT esteja presente a preocupação com a metodologia adotada durante sua oferta.

\section{METODOLOGIA}

Para a realização da pesquisa, foi usada como ferramenta a pesquisa exploratória documental. Gil (2002, p. 41) classifica as pesquisas com base nos seus objetivos e procedimentos técnicos, em que diz que a pesquisa exploratória: "tem como objetivo proporcionar maior familiaridade com o problema, como vistas a torná-lo mais explícito ou constituir hipóteses. Pode-se dizer que estas pesquisas têm como objetivo principal o aprimoramento de ideias ou a descoberta de intuições". Para tal, um dos procedimentos utilizados para sua realização é a técnica de análise documental, também conhecida como pesquisa documental. Gil (2002, p. 46) aponta que

[...] na pesquisa documental, as fontes são muito mais diversificadas e dispersas. Há, de um lado, os documentos "de primeira mão", que não receberam nenhum tratamento de órgãos públicos e instituições privadas, tais como associações científicas, igrejas, sindicatos, partidos políticos etc., [...] De outro lado, há os documentos de segunda mão, que de alguma forma já foram analisados, tais como: relatório de pesquisa, relatório de empresas, tabelas estatísticas etc.

A pesquisa foi classificada seguindo alguns critérios, que segundo Marques (2014) divide a pesquisa quanto à participação (a pesquisa é classifica como empírico-analítica, pois não houve intervenção com o objeto estudado); quanto à abordagem (é do tipo diagnóstica, uma vez que, procura conhecer como está o objeto de estudo); quanto ao método (é usado o Hipotéticodedutivo, pois a pesquisa tem sua origem a partir da hipótese elaborada e se desenvolve entorno na mesma).

O documento que foi analisado para a realização desta pesquisa é o Plano Municipal de Educação - PME, do município de Jataí - GO. Esse documento faz parte da Lei № 3.708 de 26 de junho de 2015 e foi aprovado, para o próximo decênio, pela câmara municipal de Jataí, Estado de Goiás e sancionada pelo Prefeito Municipal. 


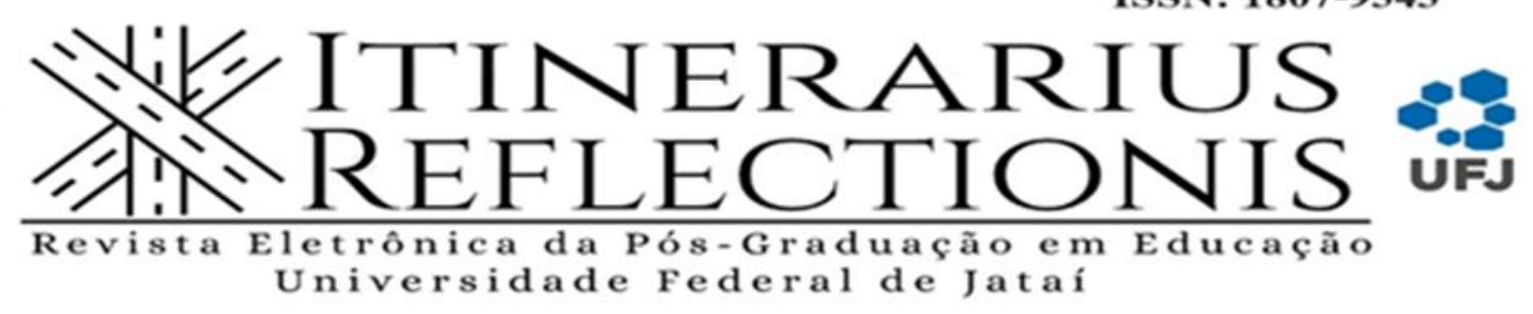

12

O estudo foi realizado no município de Jataí - GO, de acordo com o IBGE cidades, no último censo, realizado em 2010, possuía uma população de aproximadamente 88 mil habitantes e teve uma população estimada, para o ano de 2019, de aproximadamente 101 mil pessoas. Sobre a educação, os dados do ano de 2010 trazem: 97,5\% de taxa de escolarização de 6 a 14 anos de idade, o número de matrículas no ensino fundamental, em 2018, foi de 12.734 matrículas, no ensino médio, de 4.090 matrículas. O número de docentes, no ensino fundamental do ano de 2018, foi de 532, de 334 docentes do ensino médio e possui 45 escolas de ensino fundamental no ano de 2018.

Os dados apresentados acima mostram uma visão geral do município de Jataí - GO e de sua importância na região, tornando-o relevante para pesquisas em diferentes áreas do conhecimento, incluindo as áreas da educação, como por exemplo: fundamentos da educação; administração educacional; planejamento e avaliação educacional; ensino e aprendizagem; currículo; orientação e aconselhamento e tópicos específicos de educação.

A escolha do documento PME foi orientada pela hipótese de que a MAA não faz parte das estratégias educacionais das modalidades de Educação de Jovens e Adultos e da Educação Profissional e Tecnológica do município de Jataí-GO. Essa técnica de escolha, segundo Bardin (1977, p. 96), é orientada quando o “objetivo é determinado, e por conseguinte, convém escolher o universo de documentos susceptíveis de fornecer informações sobre o problema levantado".

Para o estudo, foram analisadas: a meta 7 (sete), que tem como objetivo: "fomentar a qualidade da educação básica em todas as etapas e modalidades"; a meta 10 (dez), que tem como objetivo: "oferecer, no mínimo, 25\% (vinte e cinco por cento) das matrículas de educação de jovens e adultos, nos ensinos fundamental e médio, na forma integrada à educação profissional"; e, a meta 11 (onze), que objetiva "triplicar as matrículas da educação profissional técnica de nível médio, assegurando a qualidade da oferta e pelo menos 50\% (cinquenta por cento) da expansão no segmento público". Essas metas foram selecionadas por tratarem a Educação de Jovens e Adultos (EJA), a Educação Profissional e Tecnológica (EPT) sobre a qualidade do ensino. 


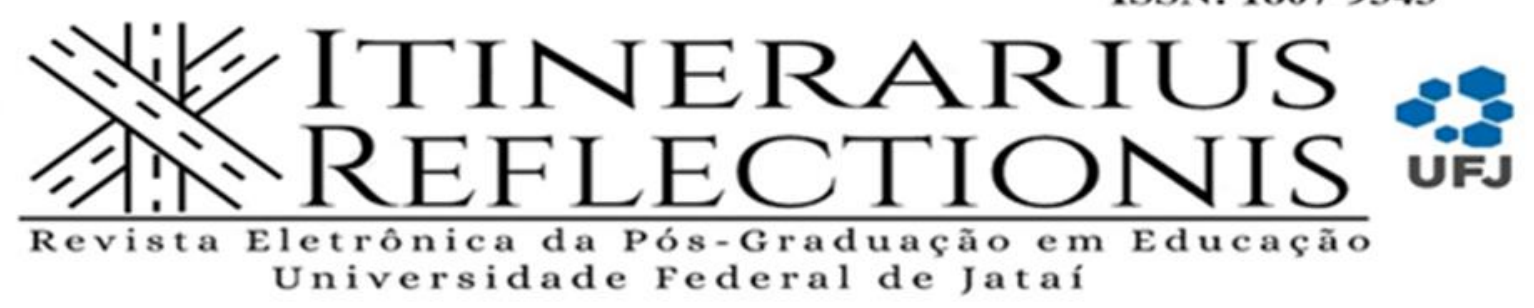

13

As metas foram escolhidas de acordo com o método de codificação desenvolvido por Bardin (1997, p. 103) diz que codificação se explica pelo fato de ser "necessário saber a razão porque é que se analisa, e explicitá-lo de modo a que se possa saber como analisar”. Por tanto, as metas selecionadas codificam o tema central da pesquisa, pois são as metas que fazem referência às estratégias educacionais do ensino para as modalidades de EJA e da EPT de JataíGO.

Dentro das metas escolhidas houve a categorização das suas estratégias, levando em consideração os critérios definidos por Bardin (1997, p. 120):

\begin{abstract}
A exclusão mútua: Esta condição estipula que cada elemento não pode existir em mais de uma divisão [...] A homogeneidade: O princípio de exclusão mútuo depende da homogeneidade das categorias [...] A pertinência: Uma categoria é considerada pertinente quando está adaptada ao material de análise escolhido, e quando pertence ao quadro teórico definido [...] Objetividade e a fidelidade: [...] As diferentes partes de um mesmo material, ao qual se aplica a mesma grelha categorial, devem ser codificados da mesma maneira. [...] Produtividade: [...] um conjunto de categorias são produtivas se fornecer resultados férteis.
\end{abstract}

A categorização deu origem a três divisões: estratégias para a EJA; estratégias para a EPT; estratégias não relacionadas diretamente. Logo, apenas as estratégias voltadas para EJA e EPT foram analisadas, sendo elas apresentadas nos quadros 2, 3 e 4.

Ao analisar essas estratégias, buscamos evidências, essas foram organizadas pelas regras de enumeração, que segundo Bardin (1997, p. 108) pode ser dividida entre "unidades de registro - o que se conta - e regras de enumeração - o modo de contagem".

Foi considerado como unidades de registro as expressões: Metodologia Ativa de Aprendizagem; Metodologia Ativa de Ensino; Método de Análise e Solução de Problemas (MASP); aluno protagonista; professor mediador; e autonomia dos alunos. As expressões usadas fazem parte do universo da MAA, permitindo, assim, a busca por evidências de forma direta e indireta. O modo de contagem escolhido foi por frequência simples, ou seja, quantas vezes as expressões aparecem nos textos das metas escolhidas. Para Bardin (1997, p. 109), a frequência simples "[...] corresponde ao postulado seguinte: a importância de uma unidade de registro aumenta com a frequência de aparição". 


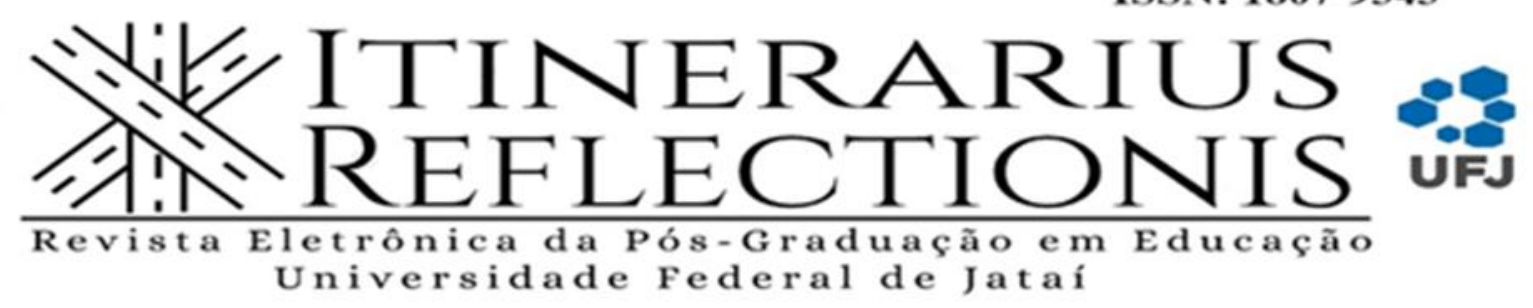

14

Escolhido o documento a ser analisado, os trechos relevantes para a pesquisa e as regras de enumeração, lemos minuciosamente das metas 7 (sete), 10 (dez) e 11 (onze) em busca das unidades de registro e a contagem de sua frequência, após a leitura foi realizada os cálculos das porcentagens das estratégias que se enquadram dentro das 3 (três) classificações.

Para realização dos cálculos foi utilizada a regra de três simples, que segundo Gouveia (2020, p.1. Grifo do autor.) "a regra de três é um processo matemático para a resolução de muitos problemas [...] Nesse sentido, na regra de três simples, é necessário que três valores sejam apresentados, para que assim, descubra o quarto valor". Neste caso os valores para realização dos cálculos são os números de estratégias de cada meta; os números de estratégias relacionadas às 3 (três) classificações; sendo o total de estratégias 100\% (cem por cento) e o número de estratégias classificadas representa a porcentagem que se deseja achar.

\section{APRESENTAÇÃO E ANÁLISE DOS DADOS}

Os trechos do PME, usados para buscar das unidades de registro e a contagem de sua frequência, de acordo com sua categorização, estão apresentados nos quadros a seguir:

Quadro 2: Estratégias e categorização - meta 7

\begin{tabular}{|c|c|}
\hline \multicolumn{2}{|l|}{ Meta 7} \\
\hline Estratégias & Categorização \\
\hline $\begin{array}{l}\text { Estabelecer e implantar diretrizes pedagógicas para a Educação Básica } \\
\text { Municipal e a base nacional comum dos currículos, com direitos e objetivos de } \\
\text { aprendizagem visando o desenvolvimento dos (as) alunos (as) para cada ano do } \\
\text { ensino fundamental respeitada a diversidade local neste ano de } 2016 \text {. }\end{array}$ & $\begin{array}{l}\text { Estratégias não } \\
\text { relacionadas diretamente }\end{array}$ \\
\hline $\begin{array}{l}\text { 2. Assegurar que no quinto ano de vigência do Plano Municipal de } \\
\text { Educação, pelo menos } 70 \% \text { (setenta por cento) dos (as) alunos (as) do ensino } \\
\text { fundamental tenham alcançado nível suficiente de aprendizado em relação aos } \\
\text { direitos e objetivos de aprendizagem em seu ano de estudo. }\end{array}$ & $\begin{array}{l}\text { Estratégias não } \\
\text { relacionadas diretamente }\end{array}$ \\
\hline $\begin{array}{l}\text { 3. Realizar junto às famílias e ao Conselho Tutelar parceria para o } \\
\text { cumprimento das atividades escolares, da frequência regular e dos atendimentos } \\
\text { especializados a partir de agosto de } 2016 \text {, por cada Unidade Escolar. }\end{array}$ & $\begin{array}{l}\text { Estratégias não } \\
\text { relacionadas diretamente }\end{array}$ \\
\hline $\begin{array}{l}\text { 4. Garantir que, no prazo de três anos, contados a partir de janeiro de } 2016 \\
\text { todas as unidades escolares da Rede Pública Municipal, promovam a adaptação }\end{array}$ & $\begin{array}{l}\text { Estratégias não } \\
\text { relacionadas diretamente }\end{array}$ \\
\hline
\end{tabular}




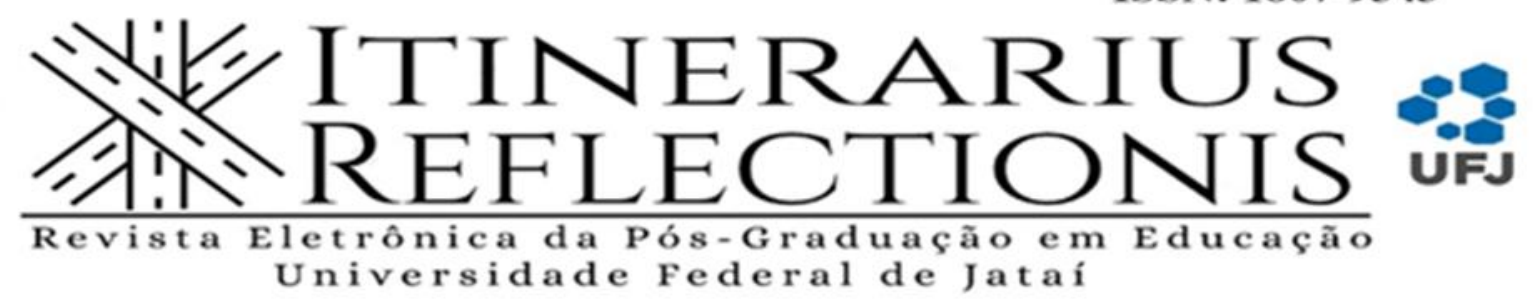

15

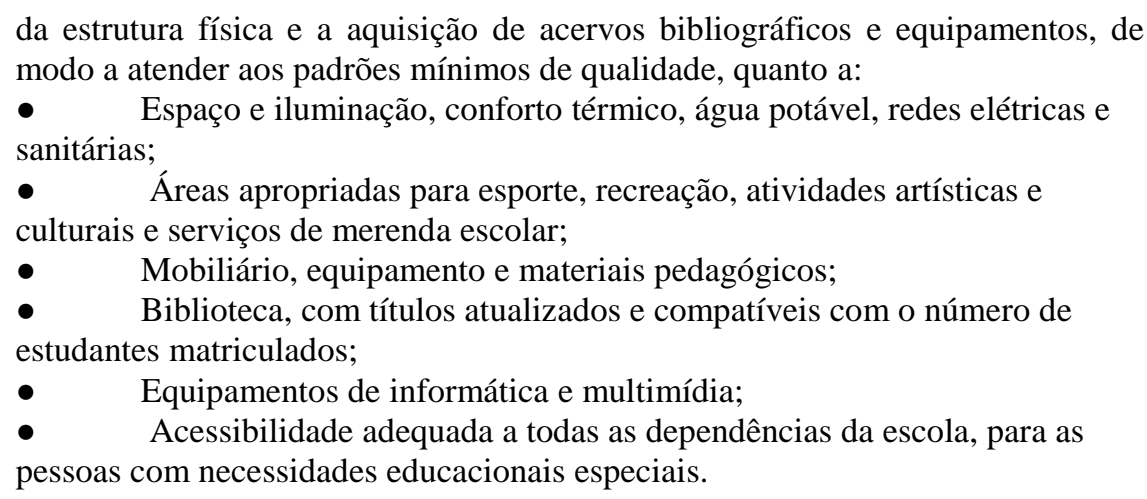

5. Garantir livros didáticos para todos os estudantes do ensino fundamental.

6. Assegurar transporte gratuito para todos (as) os (as) estudantes da educação do campo na faixa etária da educação escolar obrigatória, mediante renovação e padronização integral da frota de veículos, de acordo com especificações definidas pelo Instituto Nacional de Metrologia, Qualidade e Tecnologia - INMETRO, e financiamento compartilhado, com participação da União proporcional às necessidades dos entes federados, visando a reduzir a evasão escolar e o tempo médio de deslocamento a partir de cada situação local.

7. Disponibilizar aos estudantes do ensino fundamental do meio rural transporte escolar para outras escolas, enquanto não se constrói as escolas rurais na região.

8. Assegurar a efetiva e eficaz gestão democrática, nos termos da Lei Complementar Estadual $n^{\circ} 26 / 98$ e Resolução do Conselho Municipal de Educação no 019/2011 de outubro de 2011.

9. Elaborar políticas de combate à violência na escola, desenvolvendo ações destinadas à capacitação de educadores para detecção dos sinais de suas causas, como a violência doméstica e sexual, favorecendo a adoção das providências adequadas para promover a construção da cultura de paz e um ambiente escolar dotado de segurança para a comunidade.

10. Desenvolver currículos e propostas pedagógicas específicas para educação escolar das escolas rurais incluindo os conteúdos culturais correspondentes à respectiva comunidade e produzindo e disponibilizando materiais didáticos específicos, inclusive para os (as) alunos (as) com deficiência.

11. Promover em consonância com as diretrizes do Plano Nacional do Livro e da Leitura a capacitação de bibliotecários e outros para a formação de leitores de acordo com a especificidade das diferentes etapas do desenvolvimento e da aprendizagem a partir do ano de 2016.

12. Instituir, em articulação com as Instituições Educacionais locais programa de formação de professores para promover e consolidar política de preservação da memória nacional.
Estratégias não relacionadas diretamente

Estratégias não relacionadas diretamente

Estratégias não

relacionadas diretamente

Estratégias não

relacionadas diretamente.

Estratégias não

relacionadas diretamente

Estratégias não

relacionadas diretamente

Estratégias não

relacionadas diretamente

Estratégias não

relacionadas diretamente 


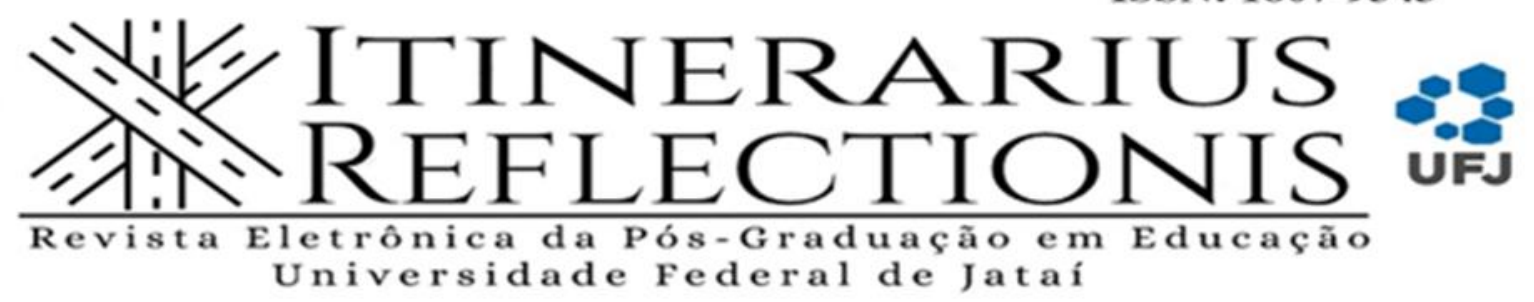

16

\begin{tabular}{|l|l|}
\hline $\begin{array}{l}\text { 13. Instituir, em articulação com as Instituições Educacionais locais } \\
\text { programa de formação de professores para promover e consolidar política de } \\
\text { preservação da memória nacional. }\end{array}$ & $\begin{array}{l}\text { Estratégias não } \\
\text { relacionadas diretamente }\end{array}$ \\
\hline $\begin{array}{l}\text { 14. Criar, elaborar e aprovar até junho de 2016 o projeto e as diretrizes de } \\
\text { escola em tempo integral pela Secretaria Municipal de Educação, em parceria com } \\
\text { as Unidades de Ensino e Conselho Municipal de Educação. }\end{array}$ & $\begin{array}{l}\text { Estratégias não } \\
\text { relacionadas diretamente }\end{array}$ \\
\hline $\begin{array}{l}15 . \quad \text { Elevar o resultado do IDEB no município de Jataí para 6,5 até o ano de } \\
2020 \text { e 7,5 até ao final da vigência deste plano. }\end{array}$ & $\begin{array}{l}\text { Estratégias não } \\
\text { relacionadas diretamente }\end{array}$ \\
\hline $\begin{array}{l}16 . \quad \text { Formação continuada na área de Educação de Jovens e Adultos, a partir } \\
\text { de 2017. }\end{array}$ & Estratégias para a EJA \\
\hline $\begin{array}{l}\text { 17. Garantir padrões de qualidade para a Educação de Jovens e Adultos, } \\
\text { como fator inadiável, já a partir de 2016. Inclusive com a avaliação de } \\
\text { desempenho da Instituição e dos servidores da Escola. }\end{array}$ & Estratégias para a EJA \\
\hline $\begin{array}{l}\text { 18. Elaborar até 2017 em parceria com a UFG, a matriz curricular específica } \\
\text { para a EJA de todas as licenciaturas. }\end{array}$ & Estratégias para a EJA \\
\hline $\begin{array}{l}\text { 19. Promover acordos de cooperação entre as principais bibliotecas da } \\
\text { cidade, de acordo com a demanda, para que se viabilize, dentro do possível, que } \\
\text { cada biblioteca possa dividir, entre elas, a responsabilidade de comprar livros, por } \\
\text { áreas de conhecimento, finalizando o projeto até 2020, com início a partir de 2017. }\end{array}$ & $\begin{array}{l}\text { Estratégias não } \\
\text { relacionadas diretamente }\end{array}$ \\
\hline
\end{tabular}

Fonte: Diário Oficial (nº. $516^{\circ}$ edição, 2015). Adaptado durante a pesquisa.

Ao analisar as estratégias relacionadas a meta 7 (sete) constatou que 15,79\% das estratégias estão ligadas a EJA (estratégias 16, 17 e 18) e que restante $(84,21 \%$ ) das estratégias não estão relacionadas diretamente.

Quadro 3 - estratégias e categorização meta 10

\section{Meta 10}

\section{Estratégia/Categorização}

1. Ofertar turmas de acordo com a demanda local identificadas pelo Estratégias não minicenso.

relacionadas diretamente

2. Publicar, a partir de 2016, para toda a população a localização das escolas Estratégias para a EJA onde será ofertada EJA. 


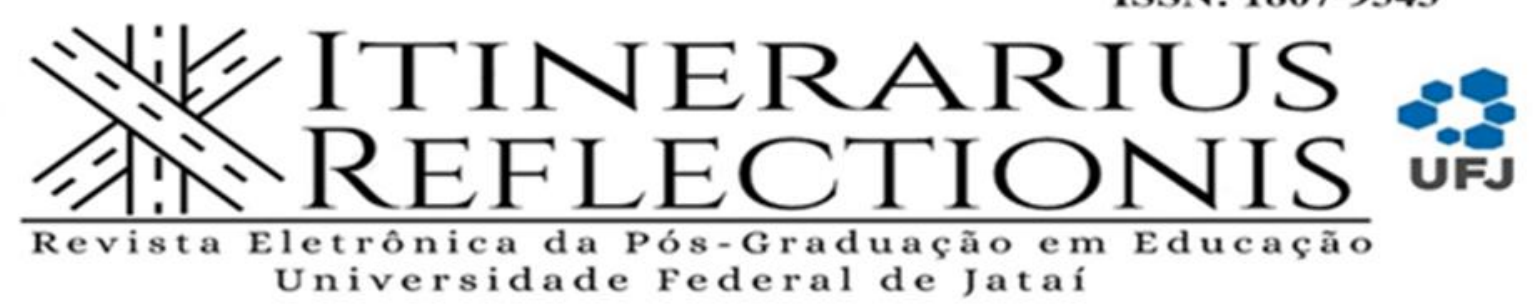

3. Estabelecer parcerias com as demais instituições de ensino e de educação Estratégias para a EPT. profissional bem como com o "Sistema S" (SESC, SENAI, SESI, SEBRAE E SENAC) a fim de concretizar para o início de 2016 a oferta de PROEJA.

4. Estruturar o Departamento de EJA a partir de 2017 com a participação da Estratégias para a EJA Universidade Federal de Goiás e outras instituições de Ensino de Superior, na definição de programas e metodologias de trabalho.

Fonte: Diário Oficial (nº $516^{\circ}$ edição, 2015). Adaptado durante a pesquisa.

Ao analisar as estratégias relacionadas a meta 10 (dez) constatou que 50\% das estratégias estão ligadas a EJA (estratégias 2 e 4) e que $25 \%$ das estratégias estão ligadas a EPT (estratégia 3) e que os outros $25 \%$ das estratégias não estão relacionadas diretamente.

Quadro 3 - estratégias e categorização meta 11

\section{Meta 11}

\section{Estratégia/Categorização}

1. Criar e atualizar, trienalmente, a partir de 2017, sob articulação das secretarias municipal, estadual de Educação, de Indústria e Comércio e outros, um banco de dados acerca das demandas do mundo do trabalho, das pesquisas teóricas sobre educação profissional e da oferta de vagas para cursos técnicos e de formação inicial e continuada, bem como socializá-las com as instituições de ensino.

2. Realizar ações, anualmente, visando contribuir para o acesso/ Estratégias para a EPT. permanência/êxito dos alunos nos cursos de Educação Profissional integrados, à educação Básica, subsequentes, integrados/EJA, por meio da parceria das instituições de Educação Profissional e Sistema S.

3. Estimular via convênios, sob a responsabilidade do Poder Público Estadual e Federal a ampliação da oferta de matrículas gratuitas de Educação Profissional Técnica de nível médio para atendimento à pessoa com deficiência e à modalidade Educação de Jovens e Adultos.

4. Articular ações, entre o Poder Público, as instituições Educação Profissional e o Sistema $S$, para a oferta de campos de estágio.

5. Fortalecer parcerias entre a União, Estado, município, Sistema S, $\quad$ Estratégias para a EPT. instituições educacionais voltadas para o ensino profissionalizante para a ampliação das matrículas e suporte para sua efetivação.

Fonte: Diário Oficial ( $\mathrm{n}^{\circ} .516^{\circ}$ edição, 2015). Adaptado durante a pesquisa. 


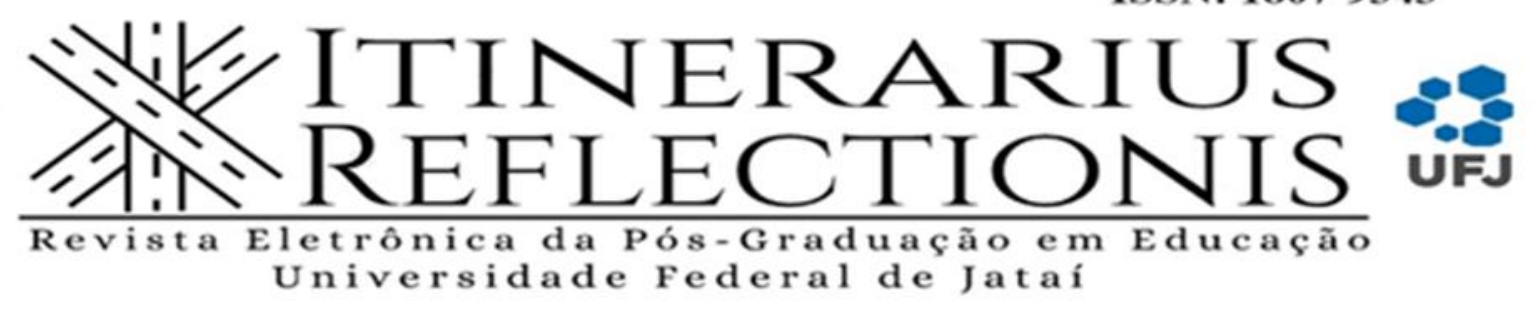

18

Ao analisar as estratégias relacionadas a meta 11 (onze) constatou que 100\% das estratégias estão ligadas a EPT.

Os resultados encontrados, sobre as unidades de registro e a contagem de sua frequência, relacionadas às estratégias selecionadas das metas 7 (sete), 10 (dez) e 11 (onze), estão apresentados na tabela a seguir:

Tabela 1: Frequência das unidades de registro

Unidades de Registro

Frequência Simples

\begin{tabular}{l|c}
\hline Metodologia Ativa de Aprendizado & 0 \\
\hline Metodologia Ativa de Ensino & 0 \\
\hline Método de Análise e Solução de Problemas (MASP) & 0 \\
\hline Aluno Protagonista & 0 \\
\hline Professor Mediador & 0 \\
\hline Autonomia dos Alunos & 0 \\
\hline
\end{tabular}

Fonte: Elaborado durante a pesquisa.

Ao analisar as estratégias ficou claro que não há menções sobre quaisquer unidades de registros consideradas para o estudo, pois as suas frequências foram iguais a 0 (zero). O que se observou foi estratégias voltadas para ampliação das ofertas de vagas relacionadas à EJA e EPT, uma preocupação em estabelecer parcerias com o sistema $\mathrm{S}$ e mapear as demandas do mercado em relação a mão de obra qualificada.

Podemos mencionar que a meta 10 (dez), estratégia 4 (quatro) - estruturar o departamento de EJA a partir de 2017 com a participação da Universidade Federal de Goiás e outras instituições de Ensino de Superior, na definição de programas e metodologias de trabalho - tem uma pequena menção sobre definir programas e metodologias de trabalho, mas não especifica qual metodologia de trabalho é essa e não é precisa que haverá algum tipo de mudança da 


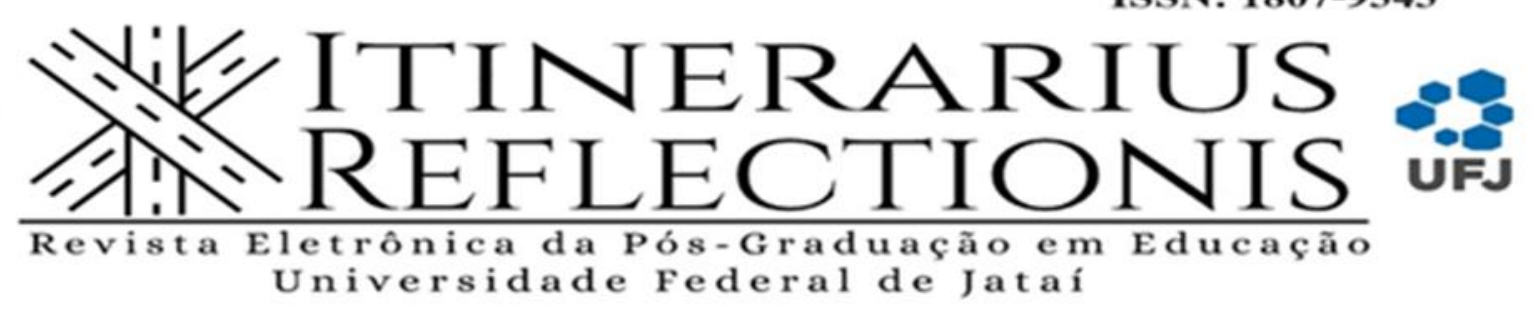

19

metodologia em sala de aula para o público do EJA, ou seja, não está dentro dos critérios considerados como evidência.

Outras estratégias que poderiam incluir a Metodologia Ativa de Aprendizagem no decorrer do seu texto são as estratégias 16 (dezesseis) e 17 (dezessete), da meta 7 (sete), pois elas fazem referência a formação continuada na área de Educação de Jovens e Adultos e sobre garantir padrões de qualidade para a Educação de Jovens e Adultos. Mas, embora sejam estratégias importantes, não foram detalhadas a ponto de mencionar como garantir os padrões de qualidade e que tipo de formação continuada será oferecida, por tanto não enquadrando como evidências.

\section{CONCLUSÕES}

Apesar das estratégias apresentadas no PME de Jataí-GO serem relevantes, é preocupante não haver sequer uma menção sobre a MAA. O PME é um documento oficial e norteia ações para o desenvolvimento da educação no município, portanto, deveria apresentar proposições no âmbito pedagógico que contemplassem metodologias variadas de ensino e aprendizagem. Principalmente, para metodologia que coloque o aluno no centro do processo.

É explícito no PME que não é uma das preocupações a serem implementadas metodologias de ensino diversificadas no decorrer dos 10 (dez) anos, tempo de validade do PME. Essa constatação corrobora a hipótese da pesquisa: MAA não faz parte das estratégias educacionais das modalidades de Educação de Jovens e Adultos e da Educação Profissional e Tecnológica do município de Jataí-GO.

É previsto que a caba 2 (dois) anos haja a revisão e a avaliação das estratégias do PME, o que permite melhorar as estratégias já estabelecidas, assim podendo acrescentar menções sobre a modernização das metodologias usadas no ensino, a fim de melhorar a qualidade do mesmo. Mas, para que isso aconteça é necessária uma equipe de profissionais que estejam atualizados com as tendências metodológicas de aprendizagem.

Como o PME é um documento que todos os municípios devem elaborar, esta pesquisa poderá ser realizada em outras cidades sem dificuldades, uma vez que o documento é de fácil 


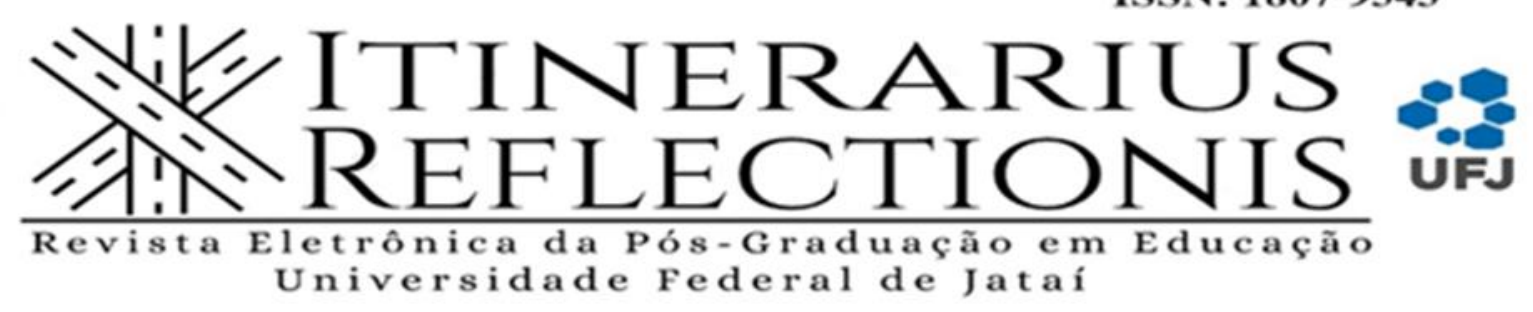

20

acesso ao público. Podendo, posteriormente, ser comparados os resultados encontrados entre os municípios, também é viável aprofundar a pesquisa documental acrescentando na análise os Projeto Político Pedagógico (PPP) das escolas que ofertam a EJA e EPT, assim procurar uma relação de causa e efeito, ou seja, avaliar se por não ter menções sobre MAA no PME os PPP seguem a mesma tendência ou não?

\section{REFERÊNCIAS}

AMARAL, Fausto do Santos; JUK, Joelson. A política de implantação da educação profissional brasileira: educação, ideologia e realidade. Educere 2017. Disponível em: https://educere.bruc.com.br/arquivo/pdf2017/26420_12512.pdf/. Acesso em 08 de abr. de 2020.

BARBOSA, E; MOURA, D. Metodologias ativas de aprendizagem na educação profissional e tecnológica. B. Tec. Senac, Rio de Janeiro, v. 39, n.2, p. 48-67, maio/ago 2013.

BARDIN, L. Análise de Conteúdo. 70 ed. São Paulo: Livraria Martins Fontes, 1979.

BRASIL no PISA 2015: análises e reflexões sobre o desempenho dos estudantes brasileiros. OCDE-Organização para a Cooperação e Desenvolvimento Econômico. São Paulo: Fundação Santillana, 2016.

BRASIL. Decreto $n^{0}$ 5.840, de 13 de julho de 2006. Dispõe sobre a implementação do Programa Nacional de Integração da Educação Profissional à Educação Básica na Modalidade de Educação de Jovens e Adultos - PROEJA. Disponível em: http://www.planalto.gov.br/ccivil_03/_Ato2004-2006/2006/Decreto/D5840.htm. Acesso em 17 de jan. de 2020.

BLIKSTEIN, Paulo. O mito do mau aluno e porque o Brasil pode ser o líder mundial de uma revolução educacional. 25 jul. 2010. Disponível em: http://www.blikstein.com/paulo/documents/books/. Acesso em 08 de dez. de 2019.

DIÁRIO OFICIAL ELETRÔNICO DO MUNICÍPIO DE JATAÍ -GO. Ano 03 / $516^{\circ}$ Edição / Vigência 26/06/2015. Disponível em: http://www.jatai.go.gov.br/secretaria-deeducacao/plano-municipal-de-educacao/ . Acesso em 04 de dez. de 2019. 


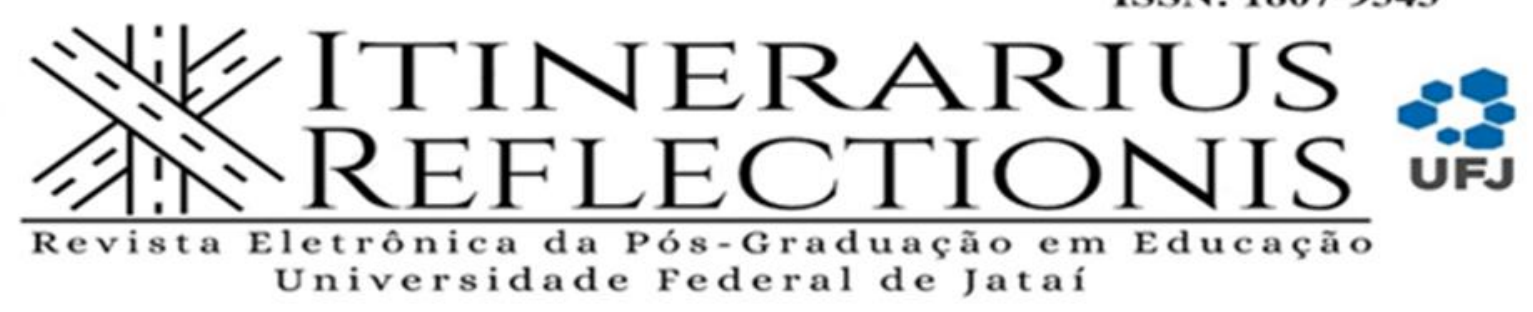

CAMARGO, F; DAROS, T. A sala de aula inovadora - estratégias pedagógicas para fomentar o aprendizado ativo. Porto Alegre: Penso, 2018. e-PUB.

GIL, A. Como elaborar projetos de pesquisa. 4 ed. São Paulo: Atlas, 2002.

GOUVEIA, Rosimar. Regra de Três Simples e Composta. 24 abr. 2020. Disponível em: https://www.todamateria.com.br/regra-de-tres-simples-e-composta/. Acesso em 15 de maio de 2020.

IBGE-Cidades. Disponível em: https://cidades.ibge.gov.br/brasil/go/jatai/panorama. Acesso em 04 de dez. de 2019.

MARQUES, Heitor Romero et. Al. Metodologia da pesquisa e do trabalho científico. 4. Ed. rev. atual. Campo Grande: UCDB, 2014.

MINISTÉRIO DA EDUCAÇÃO. Secretaria de Articulação com os Sistemas de Ensino (MEC/ SASE). O Plano Municipal de Educação: Caderno de Orientação. 2014.

Disponível em: http://pne.mec.gov.br/images/pdf/pne_pme_caderno_de_orientacoes.pdf. Acesso em 04 de dez. de 2019.

MINISTÉRIO DA EDUCAÇÃO. Diretoria de avaliação da educação básica. Relatório Brasil no PISA 2018: Versão preliminar. 2018. Disponível em:

http://download.inep.gov.br/acoes_internacionais/pisa/documentos/2019/relatorio_PISA_201 8_preliminar.pdf. Acesso em 09 de maio de 2020.

SOUSA, H; SILVA, G. Política e legislação da educação. Sobral: Instituto Superior de Teologia Aplicada, 2016.

VASCONCELlOS, Celso dos S. Metodologia Dialética em Sala de Aula. In: Revista de Educação AEC. Brasília: abril de 1992 (n. 83). 